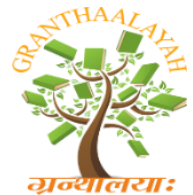

\author{
INTERNATIONAL JOURNAL OF RF
GRANTHAALAYAH \\ A knowledge Repository
}

Social

\title{
SCIENTIFIC INTEREST AND LEVEL OF CREATIVITY AMONG HIGHER SECONDARY STUDENTS IN KANYAKUMARI DISTRICT
}

\author{
Mrs. M.R. Ayishajuhi ${ }^{* 1}$, Dr. R. Sreeletha ${ }^{2}$ \\ ${ }^{* 1}$ M. Ed Scholar, M.E.T College of Education, Chenbagaramanputhur, Dist- Kanyakumari, India \\ ${ }^{2}$ Principal, M.E.T College of Education, Chenbagaramanputhur, Dist- Kanyakumari, India
}

\begin{abstract}
The present study investigated on scientific interest and level of creativity among higher secondary students in Kanyakumari district. The objective of the study was to find out the level of scientific interest and level of creativity among higher secondary students. The study also investigated to find out the significant difference in scientific interest and level of creativity among higher secondary students with respect to the gender, locality of institution, medium of instruction, type of family, type of school and religion. The investigator used normative survey method for investigation. Data was collected from a sample of 300 higher secondary students. The investigator used Scientific Interest Inventory (Ayishajuhi and Sreeletha, 2018) and Creativity test (Devishree and Sam Sandra Raj, 2009). The statistical techniques used were percentage analysis, t-test, ANOVA and Person Product moment (r). The findings revealed that the level of scientific interest and level of creativity among higher secondary students at moderate level. There was no significant difference in scientific interest and level of creativity among higher secondary students with respect to locality of school, medium of instruction, type of school and religion, but significant difference existed in the scientific interest and level of creativity among higher secondary students with respect to gender and type of family.
\end{abstract}

Keywords: Scientific Interest; Kanyakumari; Students.

Cite This Article: Mrs. M.R. Ayishajuhi, and Dr. R. Sreeletha. (2019). "SCIENTIFIC INTEREST AND LEVEL OF CREATIVITY AMONG HIGHER SECONDARY STUDENTS IN KANYAKUMARI DISTRICT." International Journal of Research - Granthaalayah, 7(12), 39-46. https://doi.org/10.29121/granthaalayah.v7.i12.2019.299.

\section{Introduction}

Science has helped the man to acquire supremacy over nature. It has greatly affected the way the people view themselves and the world around them. The wonderful achievements of science have glorified the modern world and illuminated the human creative potential. In ancient times most of the people believed that natural events and everything that happens to them is because of the actions of God and spirit, but the ancient Greeks were among the first to use systematic observation and reasoning to analyse natural happenings. 
In today's world creativity is fundamentally important for our social economic and cultural wellbeing. Unless we help the young talents to develop their innate desire to be creative, their capacity to create fails to educate them as wholesome and complete individuals. The pupils, who are encouraged to think creatively and independently, become more interested in discovering things for themselves more open to new ideas work and explore ideas.

Science has greatly revolutionized the world in the past two centuries. It has opened up ever increasing vistas of knowledge both embracing the physical as well as the psychological realities of life. Now it has emerged as a prime mover of culture, philosophy and a total way of life. Science is dynamic in nature. It gives new insight to our life with improved techniques and tools and makes the facts understand. It is because of dynamic nature, science has become indispensable part of our life and living styles. Therefore, scientific outlook is essential for all members of the society to get away from a number of irrational and superstitious beliefs. As such, a rational and just society requires development of scientific temper among the individuals up among the adolescent learners for progressive growth and modernization. The scientific way of looking at things and thinking logically as well as independently on only problematic situation, May unable to one to find out desired solution while marching ahead on the path of innovation and exploration. Science may become a way of life and enable individuals and societies to cope up with the problems likely to arise in science dominated future due to its significant role in the field of inventions and innovations, discovery of new facts and truths for explaining and elaborating old facts and findings in a new way analysing causes behind natural and super natural phenomena, finding out solutions to the ever increasing problems of human life.

\section{Need and Significance of The Study}

Science has become an integral part of our life and living. In the present context we cannot think of a world without science. The wonderful achievement of science have glorified the modern world and transformed the modern civilization into a scientific civilization. It is a way of penetrating into unexplored and un mastered realms. The present generation rests on the firm foundation laid down by the scientists with their valuable contributions.

Creativity comes from the Latin term creo "to create, make". It is generally defined as useful novelty- not novelty for its own sake but novelty that can be applied and add value to an organization's product and services. Creativity includes the generation of ideas alternatives, and possibilities. Creativity research has a long history in psychology, focusing on individual differences in personality, cognitive abilities, and problem-solving styles. However recent theoretical and empirical work looks at creativity as something the brain does naturally. That is creativity is an adaptive feature of normal cognitive functioning that evolved to aid problem solving under conditions of uncertainty. Under such circumstances, novel approaches and invention are highly advantageous. This perspective asserts that all human beings have the potential for creativity because we share common neural processes; however, whether the creativity is expressed or suppressed depends on the socio-cultural context, personality differences, and specific personal experiences (such as knowledge and skills). Within work settings, it is also apparent that organizational policies and practices as well as managerial behaviours influence creativity among workers. 


\section{Operational Definition}

\section{Scientific Interest}

Disposition to engage in activities that are appropriate to some definite object or act. It is also defined as a combination of characteristics indicative of an individual's capacity to acquire some specific knowledge, skill or set of organized responses in science.

\section{Creativity}

The ability to produce novel products or solutions to problems. Creativity has been studied as a counterpart to intelligence, represent by divergent thinking abilities.

\section{Higher secondary students}

The adolescent students studying in grade XI and XII are the higher secondary students.

\section{Objectives of the Study}

1) To find out the level of scientific interest and level of creativity among higher secondary students.

2) To find out whether there is any significant difference between higher secondary students in their Scientific Interest and level of creativity with respect to gender, locality, medium of instruction and type of family.

3) To find out whether there is any significant difference among higher secondary students in their Scientific Interest and level of creativity with respect to type of institution and religion.

\section{Hypotheses formulated for the study}

1) The level of scientific interest and level of creativity among higher secondary students is at moderate level.

2) There is no significant difference between higher secondary students in their scientific interest and level of creativity with respect to gender, locality, medium of instruction and type of family.

3) There is no significant difference among higher secondary students in their scientific interest and level of creativity with regard to the type of school and religion.

\section{Plan and Procedure \\ Method}

The investigator has adopted survey method of research to study the present topic.

\section{Population}

The population of the present study was higher secondary school students located in Kanyakumari district.

\section{Sample}

The sample of the present investigation shall include 300 higher secondary school students selected from various schools located in Kanyakumari district. 
Tools Used in the Present Study

For the present study the investigator used

- Personal Data Sheet

- Scientific Interest Inventory (Developed by AyishaJuhi.M.R Dr.R.Sreeletha Dr. R.Mukundan, 2018)

- Creativity Test (Adopted from E.Devishree and Dr.H.Sam Sandara Raj, 2009

\section{Statistical Techniques Used}

The data was analyzed by used the following statistical techniques.

- Mean

- Standard Deviation

- t-test

- ANOVA

- Pearson Product rank Correlation (r)

\section{Delimitations of the Study}

- The present study is confined to Kanyakumari district only.

- The sample has been limited to 300 higher secondary school students.

- The present study is focused only higher secondary school students.

\section{Review of Related Literature}

Jampannanavar and Yadawad (2018) investigated a relationship between scientific attitude and academic achievement in science among secondary school students. The main objectives were i) to study the relationship between scientific attitude and academic

achievement of IX standard students as a whole. (ii) to study the relationship between scientific attitude and academic achievement of IX standard boys students. (iii) to study the relationship between scientific attitude and academic achievement of IX standard girls students. (iv) to study the relationship between scientific attitude and academic achievement of IX standard rural students. (v) to study the relationship between scientific attitude and academic achievement of IX standard urban students. A sample of 400 students in Koppel district. Science Attitude Scaledeveloped by Avinash Grewal was used as tool. Pearson's Product Moment (Correlation) was used. The findings revealed that(i)the relationship between scientific Attitude and Academic Achievement in science of IX Standard students as a whole is found to be significant and positive(ii) the relationship between Scientific Attitude and Academic Achievement in Science of IX standard Boys students is found to be significant and Positive.(iii)the relationship between Scientific Attitude and Academic Achievement in science of IX standard Girls students is found to be not significant and Positive.(iv). Relationship between Scientific Attitude and Academic Achievement in Science of IX standard rural school students is found to be significant and Positive. (v)Relationship between Scientific Attitude and Academic Achievement in Science of IX standard urban school students is found to be not significant and Positive.

Sivaprakasam (2016) conducted a study on science interest and academic achievement among higher secondary biology students in relation to their mental health. The main objectives were to find out the level of science interest and achievement in biology and their mental health of higher 
secondary students. A sample consists of 400 higher secondary students. Normative survey method had been used. The tool of science interest inventory by Nellaiappan and mental health inventory by Peterbecker were used. The findings revealed that majority of higher secondary students have high level of interest in science, achievement in biology and their mental health.

Godara (2015) conducted a study of creativity of senior secondary in relation to their intelligence and gender. The main objective of the study was to find out the relation in the creativity, intelligence and gender. A sample consists of 200 of senior secondary students was taken. The researcher used D.P.A test by Dr. K.N. Sharma and group test of intelligence by Dr.R.K. Tandon. The study revealed that there is positive correlation in intelligence and creativity. Researcher also found that gender does not affect creativity in student.

Agarwal (2013) conducted a study on creativity of senior secondary school students in relation to their emotional intelligence. The main objective was to compare the high and low emotionally intelligent adolescent senior secondary students with respect to their creativity. A sample consists of 400 adolescent students. Verbal test of creative thinking by Baquer Mehdi was used to measure the creativity and Mangal emotional intelligence scale was used to measure emotional intelligent. The obtained results showed that the high emotionally intelligent adolescents had obtained higher score on all the dimensions of creativity.

\section{Hypothesis - 1}

The level of scientific interest and level of creativity among higher secondary school students is at moderate level.

\begin{tabular}{|l|l|c|c|}
\hline Variables & Levels & No. of Students & Percentage \\
\hline Scientific Interest & Low & 57 & 19.0 \\
\cline { 2 - 4 } & Medium & 179 & 59.7 \\
\cline { 2 - 4 } & High & 64 & 21.3 \\
\cline { 2 - 4 } & Total & 300 & 100 \\
\hline \multirow{5}{*}{ Level of Creativity } & Low & 40 & 13.3 \\
\cline { 2 - 4 } & Medium & 224 & 74.7 \\
\cline { 2 - 4 } & High & 36 & 12 \\
\cline { 2 - 4 } & Total & 300 & 100 \\
\hline
\end{tabular}

\section{Hypothesis - 2}

There is no significant difference between higher secondary students in their Scientific Interest and level of creativity with respect to gender, locality, medium of instruction and type of family

\begin{tabular}{|l|l|l|c|c|c|c|c|c|}
\hline Variables & $\begin{array}{l}\text { Sub } \\
\text { samples }\end{array}$ & Category & N & Mean & S. D & $\begin{array}{c}\text { t- } \\
\text { value }\end{array}$ & Remarks & $\begin{array}{c}\text { Accepted/ } \\
\text { not } \\
\text { accepted }\end{array}$ \\
\hline $\begin{array}{l}\text { Scientific } \\
\text { Interest }\end{array}$ & Gender & Male & 149 & 25.07 & 5.442 & 2.784 & Significant & $\begin{array}{c}\text { Not } \\
\text { accepted }\end{array}$ \\
\cline { 2 - 8 }
\end{tabular}


DOI: 10.5281/zenodo.3595276

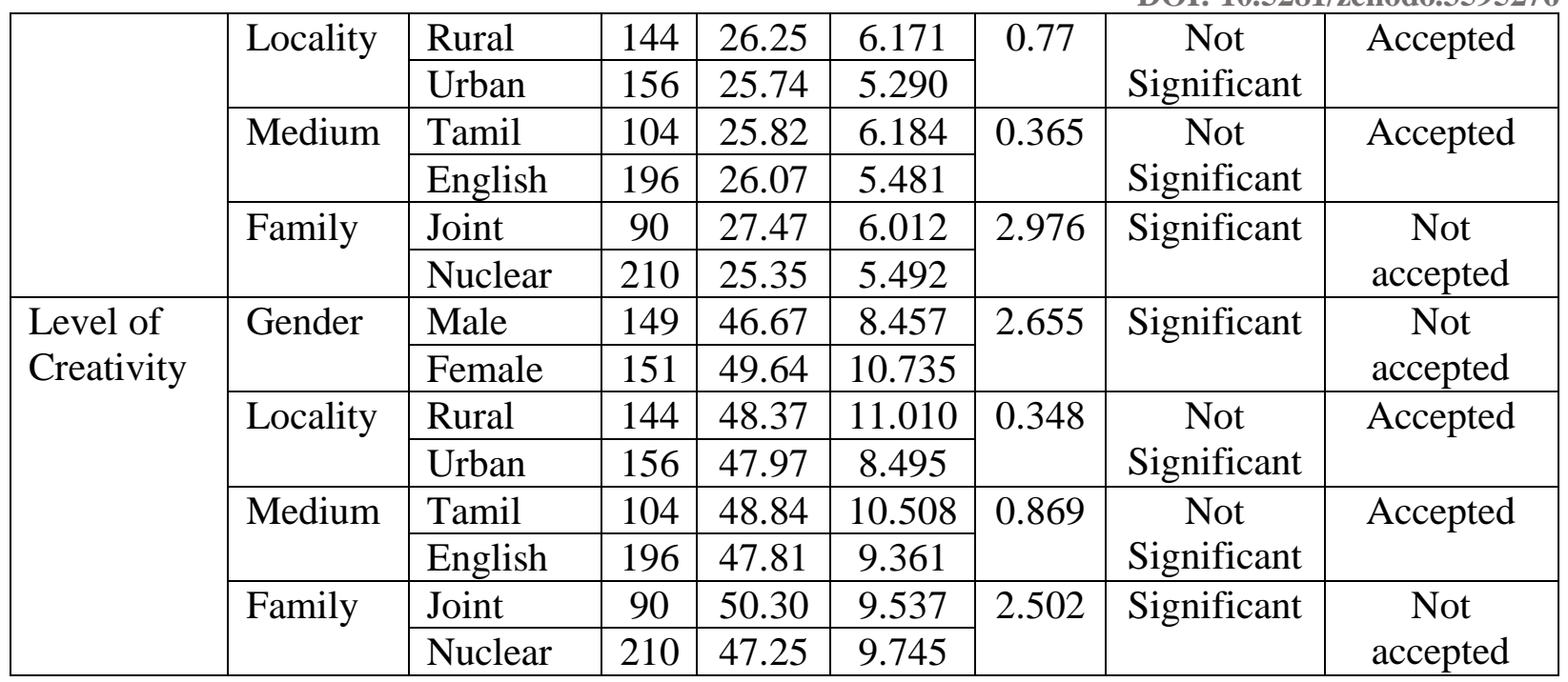

\section{Hypothesis -3}

There is no significant difference between higher secondary students in their scientific interest and level of creativity with respect to type of school and religion

\begin{tabular}{|c|c|c|c|c|c|c|c|c|}
\hline Variables & $\begin{array}{l}\text { Sub } \\
\text { samples }\end{array}$ & Source & $\begin{array}{c}\text { Sum of } \\
\text { Squares }\end{array}$ & df & $\begin{array}{c}\text { Mean } \\
\text { square }\end{array}$ & $\begin{array}{c}\text { f- } \\
\text { value }\end{array}$ & Remarks & $\begin{array}{c}\text { Accepted/ } \\
\text { not } \\
\text { accepted }\end{array}$ \\
\hline \multirow{4}{*}{$\begin{array}{l}\text { Scientific } \\
\text { Interest }\end{array}$} & \multirow{2}{*}{$\begin{array}{l}\text { Type of } \\
\text { school }\end{array}$} & Between & 20.494 & 2 & 10.247 & \multirow[t]{2}{*}{0.311} & \multirow{2}{*}{$\begin{array}{c}\text { Not } \\
\text { Significant }\end{array}$} & \multirow[t]{2}{*}{ Accepted } \\
\hline & & Within & 92954 & 297 & 234.142 & & & \\
\hline & \multirow[t]{2}{*}{ Religion } & Between & 26.116 & 2 & 13.058 & \multirow[t]{2}{*}{0.397} & \multirow{2}{*}{$\begin{array}{c}\text { Not } \\
\text { Significant }\end{array}$} & \multirow[t]{2}{*}{ Accepted } \\
\hline & & Within & 9776.800 & 297 & 32.919 & & & \\
\hline \multirow{4}{*}{$\begin{array}{l}\text { Level of } \\
\text { Creativity }\end{array}$} & \multirow{2}{*}{$\begin{array}{l}\text { Type of } \\
\text { school }\end{array}$} & Between & 181.078 & 2 & 90.539 & \multirow[t]{2}{*}{0.949} & \multirow{2}{*}{$\begin{array}{c}\text { Not } \\
\text { Significant }\end{array}$} & \multirow[t]{2}{*}{ Accepted } \\
\hline & & Within & 28349.919 & 297 & 95.454 & & & \\
\hline & \multirow[t]{2}{*}{ Religion } & Between & 245.822 & 2 & 122.911 & \multirow[t]{2}{*}{1.291} & \multirow{2}{*}{$\begin{array}{c}\text { Not } \\
\text { Significant }\end{array}$} & \multirow[t]{2}{*}{ Accepted } \\
\hline & & Within & 28285.174 & 297 & 95.236 & & & \\
\hline
\end{tabular}

\section{Findings of the Study}

The findings revealed that the level of scientific interest and level of creativity among higher secondary students at moderate level. There was no significant difference in scientific interest and level of creativity among higher secondary students with respect to locality of school, medium of instruction, type of school and religion, but significant difference existed in the scientific interest and level of creativity among higher secondary students with respect to gender and type of family.

\section{Conclusion}

- The study was designed with the objective of finding out the scientific interest and level of creativity among higher secondary students. Differential statistical techniques like 
percentage analysis, t-test and ANOVA were employed to test the hypotheses of the present study.

- From the level analysis, it can be concluded that the level of scientific interest and level of creativity among higher secondary students is at moderate level.

- From the result of t-test it can be concluded that there was no significant differences in the scientific interest and level of creativity among higher secondary students with respect to locality of school, medium of instruction, but significant difference existed in the scientific interest and level of creativity among higher secondary students with respect to their gender and type of family.

- From the result of ANOVA it can be concluded that there was no significant difference in scientific interest and level of creativity among higher secondary students with respect to their type of school and religion.

\section{Educational Implication}

The Educational Implications that are emerged from the findings of the Study are discussed.

- It will develop critical thinking skills among students.

- Teachers should practice innovative approaches so as to make the teaching process more creative.

- The written assignments and activity assignments then should develop the scientific interest among students.

- Teachers should be given training workshops and refresher programs for developing scientific interest among students through the teaching of science.

- The Scientific Interest includes several components like Interest towards the Contributions of Science, Interest towards the influence of Science in daily life, Interest towards the values related to Science, Interest towards the relationships between various branches of Science and Interest towards the career related to the field of Science.

\section{Suggestions for Further Studies}

The findings of the present study can lead to the following suggestions for their research in the field.

- A study on scientific interest and level of creativity among higher secondary students and other categories of students like high school students, arts and science students, B.Ed. students can also be conducted.

- The same study can be replicated on education, engineering and medical college faculties also.

- This study was limited to the different type of school students in Kanyakumari district. This study also extended to other district of Tamilnadu as well as to other states of India.

- This study limited only for 300 higher secondary students. It must be extended for more sample size.

- An extension of the study using more variables can be used. 


\section{References}

[1] Agarwal, S (2013). Creativity of Senior Secondary School Students in Relation to their Emotional Intelligence, Journal of Educational and Psychological Research, 3(2)

[2] Best and Khan (2006). Research in education (10th edition). Prentice hall of India private limited. New Delhi:

[3] Garrett (2005). Statistics in Psychology and Education (12th edition). Paragon International Publishers, NewDelhi.

[4] Godara (2015). Creativity of senior secondary in relation to their intelligence and gender. Psycho lingua, 34(1,2),61-63

[5] Good,T.(1945).Statistical analysis in research, published by Kithabmahal publications.

[6] Jampannanavar,G.C \& Yadawad, S.C(2018). A study of relationship between scientific attitude and academic achievement in science among secondary school students. Review of Research,7(4)

[7] Kothari,C.R.(2009). Methods and techniques, NewDelhi: widely eastern PVTLTD, 110.

[8] Sivaprakasam, J (2016). A Study on Science Interest and Academic Achievement among Higher Secondary Biology Students in Relation to their Mental Health. Journal of Educational and Psychological research, 6 (2), 199-204.

\footnotetext{
*Corresponding author.

E-mail address: ayshariya2715@ gmail.com
} 